\title{
Oxygen Chemoreceptors in Low Birth Weight Infants
}

\author{
Alfred N. Krauss, Carlos A. Tori, Jeffrey Brown, Jane Soodalter, and Peter A. M. Auld ${ }^{[19]}$ \\ Department of Pediatrics, Cornell University Medical College, New York, New York, USA
}

\begin{abstract}
Extract
Serial studies of respiratory sensitivity to altered oxygen tensions $\left(\mathrm{F}_{\mathrm{IO}_{2}}\right)$ were carried out on 39 infants ranging in birth weight from 800 to 4,140 g, and of gestational ages between 28 weeks and term. We used a modification of the Dejours single breath test to show that all infants, regardless of birth weight or gestational age, possess sensitivity to altered $\mathrm{F}_{\mathrm{IO}_{2}}$. The presence of periodic breathing or apnea on return to room air after exposure to $10 \%$ oxygen $-90 \%$ nitrogen suggests a high level of chemosensitivity to oxygen in immature infants. Neurologic immaturity does not appear to be an explanation for the apnea or periodic breathing observed in premature infants.
\end{abstract}

\section{Speculation}

The lack of sustained response to hypoxia seen by some observers may be a mechanical factor, not a neurologic one. The decreased compliance and increased resistance of lungs of neonates necessitate greater work on the part of the infant. Mechanical factors have been shown to play a part in limiting the ventilatory response to carbon dioxide in adults with obstructive disease, and the same factor may play a role in limiting the response to hypoxia in the low birth weight infant. This conclusion is suggested by the fact that a constant extrathoracic negative pressure has been shown to eliminate periodic breathing in premature infants. The present study suggests that the mode of action in this case may be either via improved mechanical factors accompanying larger lung volumes, or the effect of stabilizing the chest at a larger functional residual capacity and thus preventing oscillations in $\mathrm{Pa}_{\mathrm{O}_{2}}$, which may produce periodic breathing.

\section{Introduction}

The apnea and periodic breathing observed in low birth weight premature infants have been attributed to immaturity of the chemoreceptors [9]. Most studies of chemosensitivity to altered oxygen tension in these infants have tended to confirm this conclusion. For example, Miller and Smull [10] did not measure a sustained response to prolonged hypoxia until 60 days of age. Cross and Oppe [2] demonstrated a fall in the minute volume $\left(\dot{V}_{E}\right)$ of premature infants during the 1st minute of exposure to $15 \%$ oxygen. Although these studies indicate the presence of chemoreceptors in infants as small as $1.5 \mathrm{~kg}$ at birth, they do not provide data on very small infants, nor do their data suggest whether chemoreceptor activity is present from birth. The studies of Cross [2] as well as those of Brady et al. [1] suggest that chemoreceptor activity is fully developed at birth in term infants. The rarity of apneic attacks and periodic breathing in term infants, and their ability to sustain an increased minute volume in response to hypoxia have supported the conclusion that chemoreceptor reflexes in the low birth weight infant are immature.

It has recently been shown that subjects hypoxemic from infancy, e.g., persons native to high altitude or patients with cyanotic congenital heart disease, lack the ventilatory response to hypoxia exhibited by healthy 
people born at low altitude $[4,13,14]$. Hyperoxia causes a fall in $\dot{V}_{E}$ in cyanotic patients and high altitude natives, thus demonstrating that chemoreceptors for oxygen are in fact present. Hypoxia fails to cause a significant increase in ventilation in these subjects, suggesting that early exposure to hypoxemia permanently alters the activity of the chemoreceptors. It has been shown that nondistressed low birth weight infants maintain a low arterial oxygen saturation and arterial $\mathrm{P}_{\mathrm{O}_{2}}$ for several weeks after birth [7]. Furthermore, premature infants appear to be unresponsive to the blood gas changes occurring during apnea; thus they seem to behave like highland residents with impaired chemoreceptor activity. These observations suggested that low birth weight infants might have chemoreceptor activity similar to that of highland natives. The present investigation was undertaken to determine: (1) whether chemoreceptor activity was present in low birth weight infants, (2) whether this activity varied with maturity or postnatal age, and (3) whether the low oxygen tensions experienced by these infants in early postnatal life permanently altered this reflex activity.

\section{Methods}

The method chosen to demonstrate chemoreceptor activity was that of Dejours [3]. In this method, the concentration of inspired oxygen $\left(\mathrm{F}_{\mathrm{IO}_{2}}\right)$ is acutely altered. Minute volume $\left(\dot{V}_{E}\right)$ is measured before and during the change of $\mathrm{F}_{\mathrm{IO}_{2}}$ and the change in $\dot{\mathrm{V}}_{\mathrm{E}}$ taken as an index of the presence and strength of chemoreceptor activity for oxygen. The short duration of the stimulus enables changes in ambient oxygen to be studied in isolation, as the entire test period is finished before secondary changes in $\mathrm{pH}$ or $\mathrm{P}_{\mathrm{CO}_{2}}$, due to hypo- or hyperventilation, take place.

All patients were studied with a face mask in place. A $\mathrm{Y}$-tube attached to the mask permitted administration of room air, $10 \% \mathrm{O}_{2}-90 \% \mathrm{~N}_{2}$, or $100 \% \mathrm{O}_{2}$. Low suction at the base of the mask provided for flow of the gas and prevented build up of $\mathrm{CO}_{2}$. In a series of experiments (series I) a pneumotachygraph mask with a wire mesh screen having a resistance of $1 \mathrm{~cm} \mathrm{H} \mathrm{H}_{2} \mathrm{O} /$ liter/sec was used to record tidal volume by integration of respiratory flow. In the second series (series II), an ordinary face mask with no measurable resistance was used in order to eliminate any effect of mask resistance on ventilatory response. Tidal volume and minute volume were measured with an IMI impedance plethysmograph recording on a Sanborn 4-channel recorder. The electrodes of the plethysmograph were placed in the anterior axillary line at the level of the xiphoid. Tidal volume was derived by calibrating the plethysmograph tracing against a pediatric wedge spirometer [16]. Significant correlations between spirometry and impedance plethysmography were obtained $(r=0.6, P<0.05)$.

In series $I, 13$ preterm, weight appropriate for gestational age infants, were studied. Gestational ages were between 28 and 33 weeks, and birth weights ranged from 960 to $1,780 \mathrm{~g}$. In addition, seven full term infants who weighed between 2,700 and 4,140 $\mathrm{g}$ at birth were studied. In series II, 19 infants were studied: 6 infants under 34 weeks gestation, birth weights from 800 to $1460 \mathrm{~g} ; 10$ infants of 34-38 weeks gestation, birth weights between 1,500 and 2,050 g; and 3 term infants between 2,100 and $4,000 \mathrm{~g}$.

Infants were studied within $1 \mathrm{hr}$ after feeding. All were swaddled and warmed with a heat lamp as needed to keep environmental temperatures between $33-35^{\circ}$. All were breathing room air when studied, and no infants were ill at the time of study. Either arterial $\mathrm{P}_{\mathrm{O}_{2}}$ in room air or arterial saturation via ear oximetry [17] were performed on the study infants. In each case, saturation or an arterial oxygen tension equivalent to a saturation of $90 \%$ or better while breathing room air was obtained.

After establishing a base line of regular respirations with the mask in place, a balloon containing the test gas at room temperature and atmospheric pressure was attached to the Y-tube. While the patient was quietly breathing, this was unclamped and the arm of the Y leading to room air was simultaneously clamped. The test gas, consisting of either $10 \%, 50 \%$, or $100 \%$ oxygen was administered for $30 \mathrm{sec}$, and the patient then returned to room air. In series $I$ (pneumotachygraph mask), $\dot{V}_{\mathrm{E}}$ was recorded for $15 \mathrm{sec}$ after the test stimulus. In series $I I$ (normal mask), $\dot{V}_{\mathrm{E}}$ was recorded for $20 \mathrm{sec}$ after an 8 -sec lag period of test gas administration, and then again for $10 \mathrm{sec}$ on return to room air after another 8 -sec lag. The lag periods were introduced in order to allow for circulation of blood from the lungs to the chemoreceptor centers. During series $I$, end-tidal $\mathrm{P}_{\mathrm{CO}_{2}}$ was monitored while the test gas was administered, and was not seen to change from its values during room air breathing. Two to four runs with each test gas were carried out, and the results calculated as the percentage change in $\dot{V}_{E}$ between base line and test periods.

\section{Results}

All infants, regardless of birth weight, gestational age, and postnatal age, showed a fall in $\dot{\mathrm{V}}_{E}$ on exposure to $50 \%$ or $100 \%$ oxygen (Fig. 1). All infants showed an increase in $\dot{\mathrm{V}}_{\boldsymbol{E}}$ on exposure to $10 \%$ oxygen. When infants 


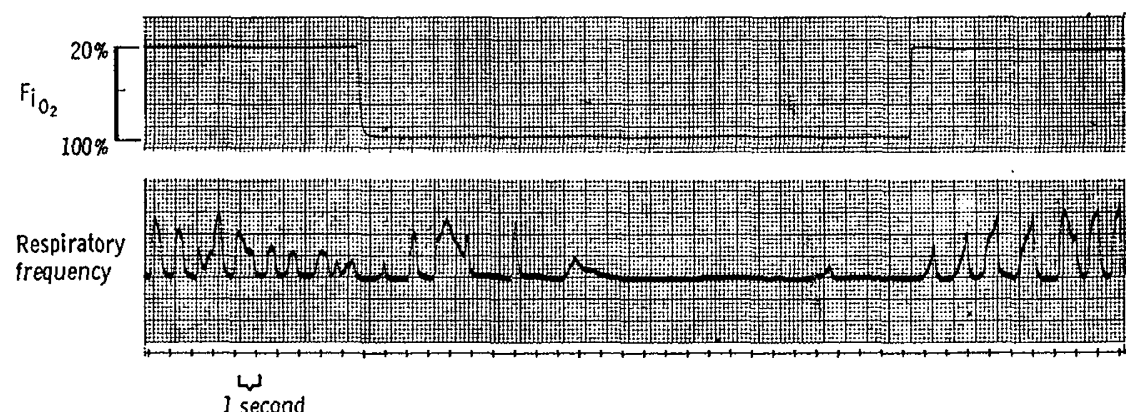

Fig. 1. Apnea following acute exposure to $100 \%$ oxygen.

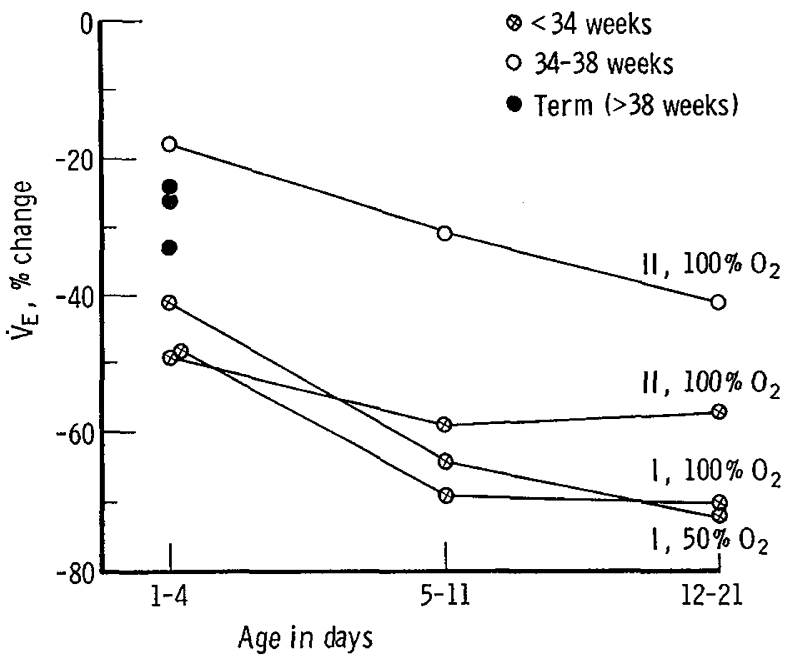

$1=\dot{V}_{E}$ estimated with pneumotachygraph

II $=\dot{V}_{E}$ estimated by plethysmography

Fig. 2. Ventilatory response to $50 \%$ and $100 \%$ oxygen. Change in minute ventilation $\left(\dot{V}_{E}\right)$ after exposure to $50 \%$ or $100 \%$ oxygen versus postnatal age in days.

were grouped by birth weight and postnatal age, no statistically significant differences were observed between groups, with two exceptions: infants of 34-38 weeks gestational age showed a greater fall in $100 \%$ oxygen at 2 weeks of age than at birth $(P<0.05)$, and infants under 34 weeks gestation showed a greater fall in $\dot{V}_{E}$ in $100 \%$ oxygen at birth than those of 34-38 weeks gestational age $(P<0.05)$. Both hypoxic and hyperoxic stimuli appeared to elicit greater responses at later postnatal ages, although differences were not statistically significant. Term infants under 1 week of age showed quantitatively similar responses to less mature infants. These results are graphically presented in Figures 2-4.

Fifty percent oxygen was as effective in reducing $\dot{V}_{E}$ as $100 \%$ oxygen. Most infants also showed a fall in $\dot{V}_{\mathbf{E}}$ when returning to room air ( $21 \%$ oxygen) from $10 \%$ oxygen.

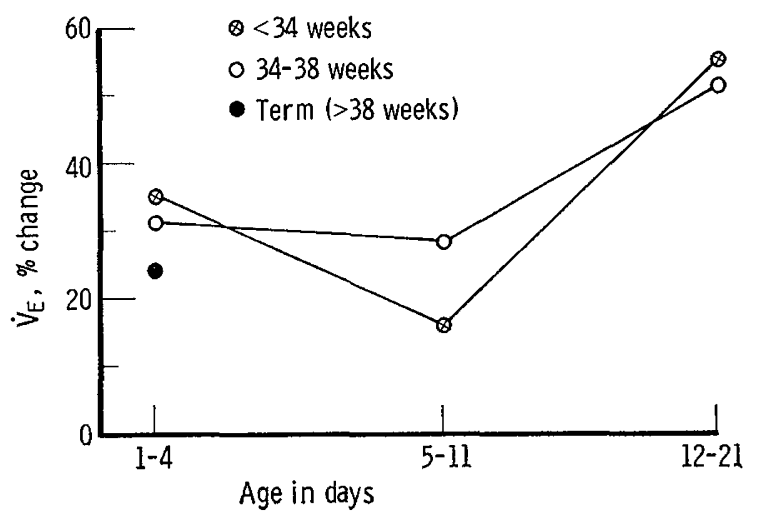

Fig. 3. Ventilatory response to $10 \%$ oxygen. Change in minute ventilation $\left(\dot{\mathrm{V}}_{\mathrm{E}}\right)$ after exposure to $10 \%$ oxygen versus postnatal age in days.

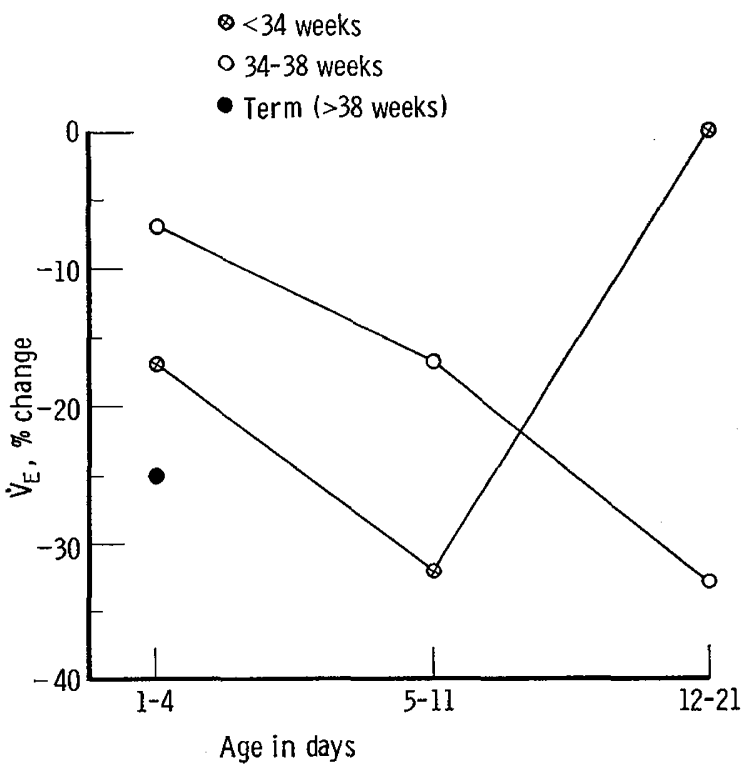

Fig. 4. Change in minute ventilation $\left(\dot{\mathrm{V}}_{\mathrm{E}}\right)$ on return to room air $\left(\mathrm{F}_{\mathrm{I}_{\mathrm{O} 2}}=21 \%\right)$ after a 30 -sec exposure to $10 \%$ oxygen $-90 \%$ nitrogen versus age in days. 




Fig. 5. Periodic breathing on return to room air $\left(\mathrm{F}_{\mathrm{I}_{2}}=21 \%\right)$ after a 35 -sec exposure to $10 \%$ oxygen-90\% nitrogen in a $1-$ month-old premature infant weighing $1,000 \mathrm{~g}$ at birth.

Table I. Incidence of changes in $\dot{\mathrm{V}}_{\mathrm{E}}$ over $25 \%$ in various groups of infants

\begin{tabular}{|c|c|c|c|c|c|c|}
\hline & \multicolumn{6}{|c|}{ Change in $\mathrm{F}_{1} \mathrm{O}_{2}$} \\
\hline & \multicolumn{2}{|c|}{ 1-4 Days of age } & \multicolumn{2}{|c|}{ 5-11 Days of age } & \multicolumn{2}{|c|}{ 12-21 Days of age } \\
\hline & $21 \%$ to $100 \%$ & $21 \%$ to $10 \%$ & $21 \%$ to $100 \%$ & $21 \%$ to $10 \%$ & $21 \%$ to $100 \%$ & $21 \%$ to $10 \%$ \\
\hline \multicolumn{7}{|l|}{ Gestational age } \\
\hline Under 34 weeks & $3 / 4(75 \%)$ & $2 / 4(50 \%)$ & $2 / 2(100 \%)$ & $1 / 3(33 \%)$ & $5 / 5(100 \%)$ & $5 / 5(100 \%)$ \\
\hline 34-38 Weeks & $6 / 12(50 \%)$ & $6 / 13(46 \%)$ & $7 / 10(70 \%)$ & $3 / 10(30 \%)$ & $7 / 9(78 \%)$ & $4 / 8(50 \%)$ \\
\hline Full term & $3 / 5(60 \%)$ & $2 / 5(40 \%)$ & & & & \\
\hline
\end{tabular}

Four infants returning to room air after inhalation of $10 \%$ oxygen developed periodic respirations with periods of apnea up to $20 \mathrm{sec}$ in durations (Fig. 5).

The incidence of changes in ventilation of $25 \%$ or greater during either hypoxia or hyperoxia in infants of varing gestational ages and postnatal ages is shown in Table I. Similar proportions of infants with a $25 \%$ or greater response were observed in all weight groups. The individual response to hypoxia could not be predicted from the response to hyperoxia. No statistical correlation between the strength of either response for individual infants could be made. Wide variations between individuals, and in the same individual tested at different times, were observed. The method for estimating $\dot{V}_{E}$ did not influence the results as no statistically significant differences between series $I$ and $I I$ were observed.

Table II. Incidence of apnea during hyperoxia in infants under 34 weeks of gestational age

\begin{tabular}{lllll}
\hline \multirow{2}{*}{ Stimulus } & \multicolumn{4}{c}{ Incidence $^{1}$} \\
\cline { 2 - 5 } & 1-4 Days of age & 5-11 Days of age & $12-21$ Days of age \\
\hline $21 \%$ to $50 \%$ & $3 / 15(20 \%)$ & $2 / 6(33 \%)$ & $4 / 9(44 \%)$ \\
$21 \%$ to $100 \%$ & $3 / 15(20 \%)$ & $4 / 7(57 \%)$ & $5 / 9(55 \%)$
\end{tabular}

${ }_{1}$ Number in parentheses indicates percentage of infants who were apneic.
The incidence of apnea of $20 \mathrm{sec}$ or longer after a hyperoxic stimulus is shown in Table II. Although there appears to be a trend toward an increased incidence of apnea after hyperoxia with increasing postnatal age, no statistically significant difference is found. Fifty percent oxygen is as effective as $100 \%$ oxygen in producing apnea.

\section{Discussion}

These results demonstrate that premature infants have qualitatively similar responses to hyperoxia and hypoxia as both term infants and adults born at sea level. They confirm and extend the results of Cross and Oppe [2] who found evidence of chemoreceptor activity in infants as small as $1.5 \mathrm{~kg}$, and of Reinsdorff and Fenner [11] who found chemoreflexes in premature infants under 3 days of age [11]. It thus appears that chemoreceptor immaturity cannot be invoked as a cause of apnea in the premature infant. The results indicate that the low oxygen tensions encountered in the premature infants are not sufficient to permanently alter the chemoreflexes for oxygen; however, further follow-up studies are needed for conclusive proof. The length of time necessary to alter these reflexes as occurs in highland natives is not known, although recent work suggests that the duration of hypoxemia is an important factor [8]. 
The results in this study do not support the contention that premature infants become more sensitive to either hypoxia or hyperoxia with either increasing maturity or increasing postnatal age. Similar percentages of infants show significant responses to hypoxia or hyperoxia despite variations in gestational or postnatal age. The lack of correlation with resting arterial oxygen tension should not be surprising, inasmuch as the final stimulus received will depend on the initial distribution of ventilation/perfusion ratios throughout the lung. The lack of correlation between the ventilatory responses to hypoxia and hyperoxia should be expected. The response to hypoxia depends on increasing the $\dot{V}_{E}$ and, therefore, on mechanical properties as well as chemosensitivity. The response to hyperoxia is not limited by the mechanical properties of the lungs, because only a decrease in $\dot{V}_{E}$ is necessary to demonstrate sensitivity. Mechanical properties of the lungs have, in fact, been shown to be a major limiting factor in the response to increased $\mathrm{CO}_{2}$ in adults [6].

Previous tests in neonates using the method of Dejours have not produced evidence of chemoreflexes [5]. However, the modification of his single breath test into a 30sec test appears to retain the virtues of an acute stimulus in avoiding alterations in $\mathrm{CO}_{2}$ tension and $\mathrm{pH}$ while providing the opportunity for a sufficient oxygen stimulus to reach the respiratory centers. By carrying out the test on infants at a suitable environmental temperature, the stimulus to ventilation occasioned by a cool environment has also been avoided. Therefore, the present study has attempted to avoid many of the objections raised to previous studies of chemoreceptor activity in the neonate. The wide variation between individuals is not surprising, inasmuch as this is found in healthy adults as well [12].

The frequent observation of apnea in 100\% oxygen, and the ability of room air to decrease ventilation following an hypoxic stimulus indicate that it is very easy to "turn off" the respirations of a low birth weight infant with too high a concentration of oxygen. This may account for the frequent occurrence of prolonged need for assisted ventilation in very low birth weight infants. The minimal oxygen concentration needed to relieve cyanosis should be used, and even room air must be used with care in assisting an apneic infant. Assisted ventilation not only reduces the hypoxic drive to breathe, but also reduces the $\mathrm{CO}_{2}$ stimuli for respiration.

\section{Summary}

The presence of oxygen chemoreceptor tone was tested with acute stimuli in 29 preterm, weight appropriate for gestational age, premature infants ranging in gestational ages from 28 to 38 weeks, and in 10 term infants. All infants hypoventilated within $10 \mathrm{sec}$ of breathing $50 \%$ or $100 \%$ oxygen, and all increased minute volume on exposure to $10 \%$ oxygen for $30 \mathrm{sec}$. The breathing of room air after $10 \%$ oxygen also acted as a hyperoxic stimulus resulting in hypoventilation. Although more mature infants showed quantitatively greater responses than less mature infants, no statistically significant differences were found between groups of different maturity. All infants, regardless of gestational age, appear to possess active chemoreceptors. Immaturity thus cannot explain the apparent lack of chemoreceptor tone seen in apneic premature infants.

\section{References and Notes}

I. Brady, J. P., Cotton, E. C., and Tooley, W. H.: Chemoreflexes in the newborn infant: Effects of $100 \%$ oxygen on heart rate and ventilation. J. Physiol. (London), 172: 332 (1964).

2. Cross, K. W., and Oppe, T. E.: The effect of high and low concentrations of oxygen on the respiration of the premature infant. J. Physiol. (London), 117: 38 (1952).

3. DfJours, P.: Control of respiration by arterial chemoreceptors. Ann. N. Y. Acad. Sci., 109: 682 (1963).

4. Edelman, N. H., Lahirei, S., And Braudo, L., et al.: Blunted ventilatory response to hypoxia in cyanotic congenital heart disease. New Engl. J. Med., 282: 405 (1970).

5. Grankd, F., Lacaisse, A., and Dejours, P.: Le stimulus $\mathrm{O}_{2}$ ventilatoire à la période néonatal chez l'homme. J. Physiol. (Paris), 52: 108 (1960).

6. King, T. K. C., AND YU, D.: Factors determining the ventilatory response to $\mathrm{CO}_{2}$ in chronic obstructive airways disease. Clin. Sci., 39: 653 (1970).

7. Krauss, A. N., AND Auld, P. A. M.: Ventilation-perfusion abnormalities in the premature infant: Triple gradient. Pediat. Res., 3: 255 (1969).

8. Lahiri, S., KaO, F. F., ANd VÉlasquez, $\mathrm{T}$, et al.: Irreversible blunted respiratory sensitivity to hypoxia in high altitude natives. Resp. Physiol., 6: 360 (1969).

9. Levine, S. Z., AND Gordon, H. H.: Physiologic handicaps of the premature infant. I. Pathogenesis. Amer. J. Dis. Child., 67: 274 (1942).

10. Miller, H. C., ANd Smull, N. W.: Further studies on the effects of hypoxia on the respiration of newborn infants. Pediatrics, 16: 93 (1955).

11. Reinsdorff, D., And Fenner, A.: Ventilatory response to hyperoxia in premature and newborn infants during the first 3 days of life. Resp. Physiol., 15: 159 (1972).

12. SCHAEFER, K. E.: Respiratory pattern and respiratory response to $\mathrm{CO}_{2}$. J. Appl. Physiol., 13: I (1958).

13. SOREnSen, S. C., and Severinghaus, J. W.: Irreversible respiratory insensitivity to acute hypoxia in man born at high altitude. J. Appl. Physiol., 25: 217 (1968).

14. Sorensen, S. C., And Severinghaus, J. W.: Respiratory insensitivity to acute hypoxia persisting after correction of tetralogy of Fallot. J. Appl. Physiol., 25: 221 (1968). 
15. Thibeault, D. W., Wong, M. M., and Auld, P. A. M.: Thoracic gas volume changes in premature infants. Pediatrics, 40: 403 (1967).

16. Med-Science Electronics, Inc., St. Louis, Mo.

17. Ear oximeter, Waters Associates, Inc., Framingham, Mass.

18. Dr. Peter Auld is supported by United States Public Health Research Grants nos. HL-09410 and HD-02644. Dr. Alfred
Krauss holds a fellowship with the Tuberculosis and Respiratory Disease Association of New York.

19. Requests for reprints should be addressed to: PETER A. M. Auld, M.D., The New York Hospital-Cornell Medical Center, Department of Pediatrics, 525 East 68th St., New York, N. Y. 10012 (USA).

20. Accepted for publication January 24, 1973. 